\title{
Estilos de aprendizaje de los Estudiantes de la Facultad de Negocios de la Universidad Católica Santa María La Antigua de Panamá
}

\author{
Vicente Herrera Montenegro ${ }^{1,2 *}$, Rodolfo Bergantino ${ }^{3}$ \\ ${ }^{1}$ Universidad Católica Santa María La Antigua, Panamá, Profesor Especial, ${ }^{2}$ Facultad de Educación, \\ Universidad de Panamá, ${ }^{3}$ Universidad Católica Santa María La Antigua, Panamá, Facultad de \\ Negocios.
}

*Autor para correspondencia. Email: vherreram@,usma.com.pa

Recibido: 26 de junio de 2019

Aceptado: 18 de julio de 2019

\begin{abstract}
Resumen
La presente investigación describe los Estilos de aprendizaje de los Estudiantes de la Facultad de Negocios de la Universidad Católica Santa María La Antigua de Panamá. Sabemos que la misión de la universidad gira en torno de la docencia, la investigación y la extensión. Centrando la atención en la primera, la enseñanza adquiere sentido en función del aprendizaje que promueve. Sin embargo, la universidad mantiene en términos generales un sistema en el cual no se realiza un seguimiento constante del aprendizaje. El conocer el estilo de aprendizaje es importante para determinar las estrategias de aprendizajes que se deben desarrollar en el aula de clase.
\end{abstract}

El resultado del estudio reflejó que la muestra de estudiantes de la Facultad de Negocios de la Universidad Católica Santa María La Antigua, tenía una media de la edad de 20.4 años y que un $52.2 \%$ son del sexo masculino Un 49.4\% (156 estudiantes) son de la carrera de Licenciatura en Negocios Internacionales. Al medir el estilo de aprendizaje de los estudiantes de la Facultad de Negocios de la USMA, vemos que prevalecen los tipos convergentes y acomodadores. Un 36.4\% son convergentes y un 35.8 son acomodadores. Por otro lado, un $14.2 \%$ son asimiladores y un $13.6 \%$ son divergentes.

Producto de conocer el estilo de aprendizaje prevaleciente, se determina que es necesario fomentar el trabajo cooperativo, dinamizan el proceso de enseñanza-aprendizaje, donde se favorezca la participación y socialización. Además, evitar la memorización mecánica del material docente, y que el alumno deja de ser receptor para ser actor de sus propios aprendizajes, y gestor de sus conocimientos.

La investigación nos lleva a señalar que los docentes de la Facultad de Negocios de la USMA deben desarrollar estrategias didácticas tales como: Simuladores de Negocios, Investigaciones y uso de 
Programas estadísticos, Ferias y exposiciones, Exposición abierta, Estudio de caso y Mapa conceptual y redes semánticas.

Palabras clave: Aprendizaje, Enseñanza, Estilos de aprendizaje, Educación superior, Estrategias didácticas.

\begin{abstract}
This research describes the learning styles of the students of the Business School from the Catholic University Santa María La Antigua in Panama. We know that the mission of the university revolves around teaching, research and extension. Focusing attention on the first one, the teaching acquires meaning in function of the learning that it promotes. However, the university maintains in general terms a system in which there is no constant monitoring of learning. Knowing the learning curve is important in order to define the learning strategies that must be developed in the classroom.
\end{abstract}

The results of the study showed that the sample of students from the School of Business from Catholic University Santa María La Antigua had an average age of 20.4 years and that $52.2 \%$ are male. About 49.4\% (156 students) are of the Bachelor's Degree in International Business. By measuring the learning style of students at the USMA School of Business, we see that convergent and accommodated types prevail. $36.4 \%$ are convergent and 35.8 are accommodated. On the other hand, $14.2 \%$ are assimilators and $13.6 \%$ are divergent.

Product of the knowledge in the prevailing learning style, it is determined that it is necessary to encourage cooperative work, they stimulate the teaching-learning process, where participation and socialization are favored. In addition, it avoids the mechanical memorization of teaching material, and that the student stops being a receiver to be an actor of their own learning, and manager of their knowledge.

The research leads us to point out that teachers of the Business School at USMA must develop didactic strategies such as: Business Simulators, Investigations and use of Statistical Programs, Fairs and Exhibitions, Open Exposure, Case Study, Conceptual Map and networking semantics Keywords: Learning, Teaching, Learning styles, Higher education, Teaching strategies.

\title{
1 Introducción
}

El aprendizaje es una de las funciones más importantes del ser humano, ya que en este intervienen diversos factores que permiten adquirir nuevas experiencias que les va dejando un nuevo aprendizaje. El aprendizaje es el proceso a través del cual se adquieren nuevas habilidades, destrezas, conocimientos, conductas o valores como resultado del estudio, la experiencia, la instrucción, el razonamiento y la observación.

El aprendizaje es un fenómeno social, por lo que podemos aprender de otros. Las emociones son uno de los factores más influyentes en los procesos de enseñanza y aprendizaje. Por lo tanto, orientar a los estudiantes para que logren gestionar sus emociones puede ayudarlos a que se adapten mejor a los nuevos contextos de aprendizaje y temas por estudiar. Asimismo, puede ayudar a promover la cohesión grupal y la paz social, a impulsar la creatividad y la cooperación, a fortalecer la motivación, a potenciar la memoria, a coadyuvar en el razonamiento y en la toma de decisiones, y a evocar lo aprendido de manera más efectiva. 
Las universidades juegan un papel importante al ser las generadoras de nuevo conocimiento. la educación aparece como protagonista de la transformación social, permitiendo fomentar la capacidad creativa de los estudiantes en todos los niveles educativos, elevando de esta manera la creatividad al nivel del valor social, convirtiéndola en un reto creativo para todos (Klimenko, 2008).

Sabemos que la misión de la universidad gira en torno de la docencia, la investigación y la extensión. Centrando la atención en la primera, la enseñanza adquiere sentido en función del aprendizaje que promueve. Sin embargo, la universidad mantiene en términos generales un sistema en el cual no se realiza un seguimiento constante del aprendizaje. Entre la clase y el examen queda un espacio en el cual el alumno aprende. Se da por supuesto que todo alumno que ingresa "sabe" aprender y que todo profesor "sabe" cómo aprenden sus alumnos.

Como integrantes de la comunidad educativa universitaria percibimos que la preocupación por hacer efectiva la acción de la universidad suele concretarse en la revisión y ajuste de planes de estudio, de servicios, de normativa, etc. Sin embargo, creemos que avanzar hacia una universidad que optimiza lo posible, reclama recuperar también las percepciones de alumnos y profesores en tanto protagonistas del hecho educativo con la expectativa de contribuir a la excelencia y a la calidad en términos de preparación profesional y desarrollo personal de los universitarios (MorchioI \& Fresquet, 2014).

\section{Estilos de aprendizaje}

El término 'estilo de aprendizaje' se refiere al hecho de que cuando queremos aprender algo cada uno de nosotros utiliza su propio método o conjunto de estrategias. Aunque las estrategias concretas que utilizamos varían según lo que queramos aprender, cada uno de nosotros tiende a desarrollar unas preferencias globales. Esas preferencias o tendencias a utilizar más unas determinadas maneras de aprender que otras constituyen nuestro estilo de aprendizaje.

Que no todos aprendemos igual, ni a la misma velocidad no es ninguna novedad. En cualquier grupo en el que más de dos personas empiecen a estudiar una materia todos juntos y partiendo del mismo nivel, nos encontraremos al cabo de muy poco tiempo con grandes diferencias en los conocimientos de cada miembro del grupo y eso a pesar del hecho de que aparentemente todos han recibido las mismas explicaciones y hecho las mismas actividades y ejercicios. Cada miembro del grupo aprenderá de manera distinta, tendrá dudas distintas y avanzará más en unas áreas que en otras.

Las diferencias en el aprendizaje son el resultado de muchos factores, como por ejemplo la motivación, el bagaje cultural previo y la edad. Pero esos factores no explican porque con frecuencia nos encontramos con alumnos con la misma motivación y de la misma edad y bagaje cultural que, sin embargo, aprenden de distinta manera, de tal forma que, mientras a uno se le da muy bien redactar, al otro le resultan mucho más fácil los ejercicios de gramática. Esas diferencias sí podrían deberse, sin embargo, a su distinta manera de aprender.

El concepto de los estilos de aprendizaje está directamente relacionado con la concepción del aprendizaje como un proceso activo. Si consideramos que el aprendizaje equivale a recibir información de manera pasiva lo que el alumno haga o piense no es muy importante, pero si entendemos el aprendizaje como la elaboración por parte del receptor de la información recibida parece bastante evidente que cada uno de nosotros elaborará y relacionará los datos recibidos en función de sus propias características. 
En conclusión, los estilos de aprendizaje señalan la manera en que el estudiante percibe y procesa la información para construir su propio aprendizaje, éstos ofrecen indicadores que guían la forma de interactuar con la realidad (Castro, 2005).

\section{Estudios de los estilos de aprendizaje}

García Cué (2006) realizó un análisis de las distintas teorías sobre los Estilos de Aprendizaje que habían sido propuestas por investigadores tales como Kolb (1976), Dunn y Dunn (1978), Keefe (1979), Honey y Mumford (1986), Felder y Silverman (1988), Alonso, C., Gallego D., Honey, P. (1994). Reid (1995), Guild y Garger (1998), Riding y Rayner (1999) y Willis y Hodson (1999), entre otros (Cué, 2012).

La mayoría de ellos, además de sugerir sus propias teorías, han diseñado y probado sus instrumentos para medir y distinguir las preferencias en cuanto a los Estilos de Aprendizaje. Uno de éstos, es el Cuestionario Honey-Alonso de Estilos de Aprendizaje (CHAEA) propuesto por Catalina Alonso en 1992 y que ha sido empleado en diferentes investigaciones en universidades Hay dos clasificaciones de estilos de aprendizaje muy estudiadas: la sensorial y la de Kolb. Debemos recordar que el estilo que tiene una persona para aprender resulta de una combinación de distintos factores: cognitivos, afectivos y psicológicos.

\section{La clasificación sensorial}

La clasificación sensorial, también denominada VAK, destaca que todos tenemos un sentido favorito y que podemos mejorar el aprendizaje si contemplamos estas preferencias sensoriales. Principalmente, se distinguen 3 grandes sistemas para aprender la información recibida:

- Visual: Es un estilo relacionado con ver y leer. Los alumnos visuales prefieren leer a escuchar y captan grandes cantidades de información solo mirando, piensan en imágenes, y visualizan en detalle. Tienen más facilidad para recordar grandes cantidades de información con rapidez. Además, visualizar les ayuda a crear relaciones entre diferentes ideas y conceptos. Realizan resúmenes y esquemas, subrayan y escriben en los márgenes de los libros, siempre toman apuntes en clase.

Suelen responder mejor a exámenes escritos.

Algunos ejemplos de acciones relacionadas: ver, mirar, leer, imaginar, buscar diferencias, comparar imágenes, escribir, pintar o dibujar. Ejemplos de recursos útiles para este tipo de estudiantes: diagramas, esquemas, imágenes, películas, enciclopedias, mapas, folletos, revistas, internet, diccionarios, dibujos, fotografías, cartas, emails, documentales, crucigramas, obras de arte, diapositivas, power points o mensajería instantánea, entre otros.

- Auditivo: Este estilo está relacionado con hablar y escuchar, sirviendo para unir ideas o elaborar conceptos abstractos con la misma destreza y rapidez que el sistema visual. Los alumnos auditivos Prefieren escuchar que leer. Si tienen que leer, les gusta hacerlo en alto.

Aprenden mediante explicaciones orales y muestran más destreza para aprender idiomas y música. Se graban para estudiar y escuchan sus grabaciones, repasando los apuntes en voz alta y hablando consigo mismos. Siguen instrucciones orales diligentemente y les gusta 
estudiar en grupo para poder debatir y contrastar. También suelen responder mejor a exámenes orales.

Algunos ejemplos de acciones relacionadas: escuchar, oír, cantar, telefonear, debatir, contar, narrar, preguntar o responder. Ejemplos de recursos útiles para este tipo de estudiantes: canciones, dispositivos móviles, vídeos, grabaciones propias y ajenas, documentales, películas, vídeo, charlas, conferencias, radio en streaming o mensajería instantánea, entre otros.

- Kinestésico: Este estilo está relacionado con tocar y hacer. El aprendizaje suele ser más lento que cualquiera de los otros dos y se necesita más tiempo. Los alumnos táctiles, captan información a través de sensaciones y movimientos, suelen hacer dibujos o esquemas en vez de copiar al pie de la letra los apuntes. Estudian moviéndose y haciendo pausas frecuentes, también les gusta estudiar en grupo. - Relacionan los nuevos conocimientos con los que ya tenían y con la vida real.

Suelen responder mejor a exámenes de carácter práctico o de laboratorio.

Algunos ejemplos de acciones relacionadas: tocar, sentir, moverse, andar, correr, saltar, cocinar, interpretar, oler o bailar. Ejemplos de recursos útiles para este tipo de estudiantes: barro, plastilina, piezas de construcción, crucigramas, juegos de mesa, mapas, instrucciones, recetas, diccionarios, enciclopedias, excursiones o visitas, entre otros.

Para evaluar qué método utilizamos con mayor frecuencia, nos podemos hacer la pregunta: ¿Qué recuerdas después de que te presenten a alguien, su cara (visual), su nombre (auditivo) o la impresión o sentimiento (kinestésico) que la persona te produjo?

La mayoría de personas empleamos los tres sistemas de manera desigual. Potenciamos unos más otros y se desarrollan proporcionalmente al uso que de ellos se haga. Por lo general, absorbemos con mayor facilidad aquella información que viene por la vía que más empleamos y a la que estamos acostumbrados.

\section{La clasificación de David Kolb}

David Kolb, un teórico educativo de procedencia estadounidense, creía que el aprendizaje se desarrollaba a partir de tres factores causales: genética, experiencias de la vida y experiencias del entorno.

Con el tiempo este modelo se ha convertido en uno de los supuestos acerca del aprendizaje con más reconocimiento y unos de los más utilizado en las universidades. Según el modelo de estilo de aprendizaje desarrollado por Kolb cuando una persona quiere aprender algo esta debe procesar y trabajar la información que recoge. Para que este procesamiento de la información se realice de manera óptima deben completarse cuatro fases distintas. Son las siguientes.

- Experiencia concreta (EC)

Deben darse lugar las experiencias inmediatas y específicas que dan pie a la observación.

- Observación reflexiva (OR)

La persona reflexiona acerca de lo que está observando y elabora una serie de hipótesis generales sobre lo que la información recibida pueda significar. 
- Conceptualización abstracta (CA)

A continuación, a raíz de estas hipótesis se forman los conceptos abstractos y las generalizaciones.

- Experimentación activa (EA)

Finalmente, la persona experimenta o practica con estos conceptos en otros contextos o situaciones.

Cuando la persona finaliza todas estas etapas del proceso, la secuencia se reinicia para seguir adquiriendo más conocimientos e información.

La realidad es que las personas tienden a especializarse en una o dos de las cuatro fases que hemos visto. Dado que Kolb advirtió de este hecho, elaboró cuatro tipologías de alumnos según la forma en la que estos prefieren trabajar la información.

Estos alumnos se clasifican en:

- Alumnos activos o divergentes.

- Alumnos reflexivos o asimiladores.

- Alumnos teóricos o convergentes.

- Alumnos pragmáticos o acomodadores.

Estas categorías, que serán explicadas una por una en el siguiente punto, hacen referencia al tipo de aprendizaje en el que se especializa una persona. En función de en la categoría que esta se encuentre le será más fácil o difícil asimilar la información, esto dependerá de la forma en la que se le presente y según se trabaje en el aula.

Tal y como se describe anteriormente, Kolb elabora una clasificación de los estilos de aprendizaje según las preferencias que tengan los alumnos a la hora de manejar y asimilar la información que se les presenta.

\section{Alumnos activos o divergentes}

Las características distintivas de los alumnos activos o divergentes incluyen una involucración y un compromiso completo y sin ningún tipo de prejuicio. Esta persona tiene a aprovechar al máximo el momento y suelen entregarse a los acontecimientos.

Se sienten entusiasmados ante cualquier tipo de actividad novedosa a la cual se entregan completamente. No obstante, tienden a aburrirse con facilidad, por lo que en el momento en el que pierdan el interés en una empezarán con otra diferente.

Otro punto que define a estas personas es que tienden a actuar antes de pensar bien las consecuencias. Veremos a continuación en que situación aprenden mejor, y en qué situación aprenden peor. 


\begin{tabular}{|c|c|c|}
\hline Tipo de alumno & Aprenden mejor cuando & Aprenden peor cuando \\
\hline $\begin{array}{l}\text { Alumnos activos o } \\
\text { divergentes }\end{array}$ & $\begin{array}{l}\text { - La actividad les suponga un } \\
\text { desafío. } \\
\text { - Les proponen actividades } \\
\text { cortas y concisas. } \\
\text { - Se sienten emocionados con } \\
\text { la actividad. }\end{array}$ & $\begin{array}{l}\text { - Son actividades a largo plazo. } \\
\text { - Tienen un papel pasivo en la } \\
\text { actividad. } \\
\text { - Deben asimilar, analizar e } \\
\text { interpretar datos. } \\
\text { - Tienen que trabajar en } \\
\text { solitario. }\end{array}$ \\
\hline
\end{tabular}

\section{Alumnos reflexivos o asimiladores}

Estos alumnos se caracterizan por observar los acontecimientos y tratar la información desde muchos puntos de vista distintos. Su especialidad es la de recolectar la información y examinarla minuciosamente antes de realizar sus hipótesis.

Su manera de trabajar les obliga a ser cautelosos con sus conclusiones, analizando todas las consecuencias de sus acciones antes de realizarlas. Siempre observan, atienden y prestan atención a todos los detalles antes de realizar cualquier aportación. Veremos a continuación en que situación aprenden mejor, y en qué situación aprenden peor.

\begin{tabular}{|l|l|l|}
\hline Tipo de alumno & Aprenden mejor cuando & Aprenden peor cuando \\
\hline $\begin{array}{l}\text { Alumnos reflexivos o } \\
\text { asimiladores }\end{array}$ & $\begin{array}{l}\text { Pueden observar } \\
\text { detenidamente la } \\
\text { información que les rodea. }\end{array}$ & $\begin{array}{l}\text { Se les obliga a } \\
\text { tener protagonismo o } \\
\text { ser en centro de atención. }\end{array}$ \\
& $\begin{array}{l}\text { Les ofrecen tiempo de } \\
\text { analizar y reflexionar antes } \\
\text { de actuar. }\end{array}$ & $\begin{array}{l}\text { No se les da el tiempo } \\
\text { suficiente para realizar una } \\
\text { tarea. }\end{array}$ \\
& $\begin{array}{l}\text { Pueden pasar } \\
\text { desapercibidos. }\end{array}$ & $\begin{array}{l}\text { Se les obliga a actuar sin } \\
\text { reflexionar antes. }\end{array}$ \\
& &
\end{tabular}

\section{Alumnos teóricos o convergentes}

Este tercer tipo de alumnos tiende a acomodar e integrar la información convirtiéndola en teorías complejas y con una lógica fundamental sólida. Su pensamiento se organiza de forma secuencial, recorriendo una serie de pasos antes de generar cualquier tipo de conclusión.

Tienen a examinar y resumir toda la información, y valoran por encima de todo la lógica y la razón, por lo que se sienten desorientados ante actividades que no poseen una lógica evidente y los juicios 
subjetivos. Veremos a continuación en que situación aprenden mejor, y en qué situación aprenden peor.

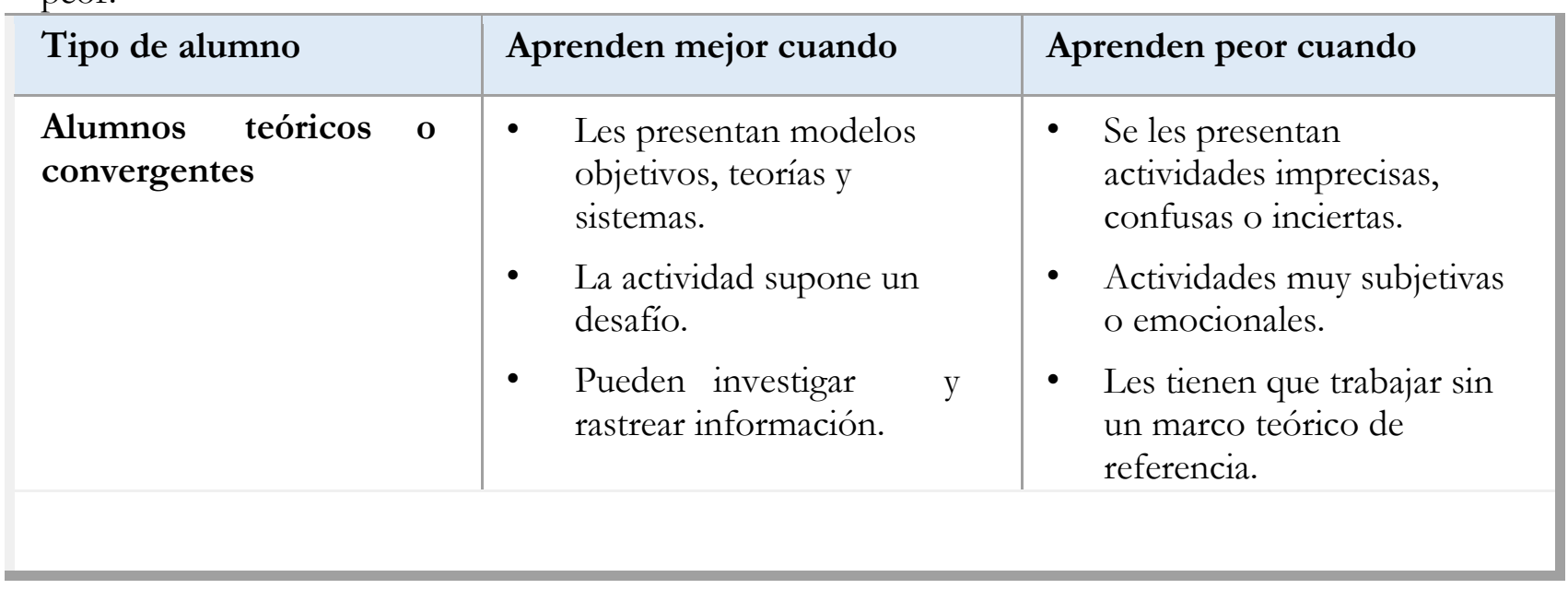

\section{Alumnos pragmáticos o acomodadores}

Los alumnos pragmáticos se sienten cómodos poniendo en práctica los nuevos conocimientos, las teorías y las técnicas que van aprendiendo. Les disgusta tener que estar debatiendo estas teorías o tener que reflexionar continuamente la información que se les presenta.

En resumen, son personas prácticas, realistas, con una gran capacidad de resolución de problemas y que siempre buscan la mejor manera de hacer las cosas.

\begin{tabular}{|c|c|c|}
\hline Tipo de alumno & Aprenden mejor cuando & Aprenden peor cuando \\
\hline $\begin{array}{l}\text { Alumnos pragmáticos o } \\
\text { acomodadores }\end{array}$ & $\begin{array}{l}\text { - Se les ofrecen actividades } \\
\text { en las que puedan } \\
\text { relacionar las teorías con } \\
\text { situaciones prácticas. } \\
\text { - Cuando pueden observar } \\
\text { cómo se realiza una } \\
\text { actividad. } \\
\text { - Cuando pueden poner en } \\
\text { práctica lo que deben } \\
\text { aprender. }\end{array}$ & $\begin{array}{l}\text { - Se presentan actividades } \\
\text { abstractas que no se } \\
\text { relacionan con la realidad. } \\
\text { - La actividad no tiene una } \\
\text { finalidad establecida. } \\
\text { - No pueden relacionar la } \\
\text { información con } \\
\text { situaciones prácticas. }\end{array}$ \\
\hline
\end{tabular}

\section{Críticas al modelo de Kolb}

Este modelo ha sido ampliamente criticado por aquellos que defienden que existe muy poca evidencia que respalde la existencia de estos estilos. Una revisión de este modelo realizado a gran escala concluyó que no existía suficiente investigación ni evidencia empírica que respalde la existencia de estos estilos. Asimismo, sus detractores insisten en que Kolb no tuvo en cuenta cómo la cultura y el contexto moldean el proceso de aprendizaje. 


\section{Métodos}

La investigación se enmarcó dentro del paradigma cuantitativo, porque permitió medir, los estilos de aprendizaje de los estudiantes de la Facultad de Negocios. Para esta investigación se utilizó la escala de Estilos de Aprendizaje de David Kolb, que ha sido demostrada su confiabilidad en múltiples estudios. Se considera que el inventario de estilos de aprendizaje que presenta unos resultados más favorables en cuanto a las propiedades psicométricas es el de Kolb (1985).

David Kolb establece 4 capacidades que son: Experiencia concreta (EC), observación reflexiva (OR), conceptualización abstracta (CA) y experimentación activa (EA) se desprenden los cuatro estilos de aprendizaje. Estas se suman sus puntos en cada casilla. Para determinar su estilo de aprendizaje, debe calcular la relación establecida entre las cuatro modalidades de aprendizaje medidas en el test. Esto se logra usando dos combinaciones de puntajes: "CA" menos "EC" y "EA" menos "OR". Utilice la tabla siguiente para registrar estas restas.

$$
\begin{array}{cr}
\text { Puntaje columna CA } & \begin{array}{r}
\text { Puntaje columna EA } \\
\text { Puntaje columna EC }
\end{array} \\
\text { Resta CA - EC } & \text { Resta EA - OR }
\end{array}
$$

Los valores obtenidos en estas restas deben marcarse en el sistema de coordenadas que se entrega a continuación. En el eje vertical debe marcarse la puntuación obtenida en la resta CA EC, y en el eje horizontal el valor obtenido de la resta de EA - OR.

Marque el punto de intersección de estos dos valores y determine el cuadrante que corresponda a su estilo de aprendizaje (acomodador, divergente, convergente o asimilador).

EC

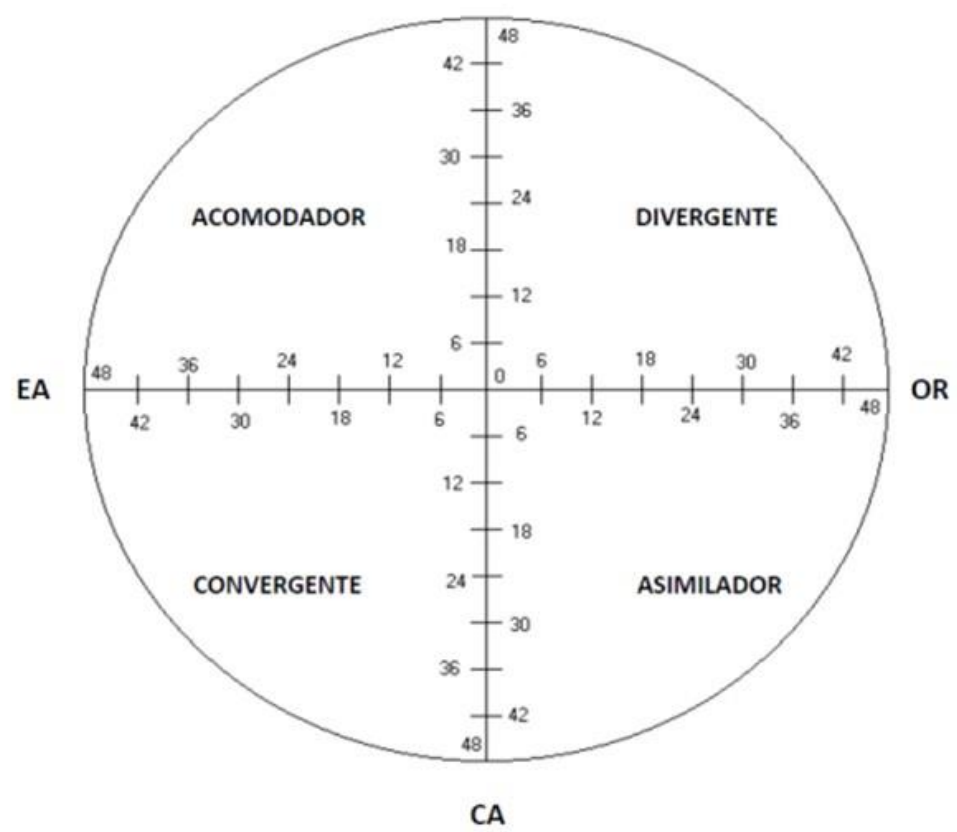

Figura 1: Grilla de resultados. Modelo de Daid Koolb. 
La investigación es de un enfoque cuantitativo, de tipo descriptiva, y de diseño no experimental, dado que no se manipulan variables.

El cálculo de muestra fue de 278 estudiantes con los parámetros siguientes:

- Confiabilidad de 95\%

- P (probabilidad de éxito) .5

- Error de 5\%

Se aplicaron 316 cuestionarios, con lo cual se supera los 278 como mínimo de la muestra.

\section{Resultados}

Se presenta la información sobre la edad de los estudiantes que conforman la muestra en la Figura 2. La muestra de estudiantes de la Facultad de Negocios de la Universidad Católica Santa María La Antigua, indica que la media de la edad fue de 20.4 años, con una desviación estándar de 2.2. años. El rango fue de 22 años, ya que la edad mínima fue de 18 años y la máxima de 40 años.

\begin{tabular}{|c|c|c|}
\hline \multirow[t]{2}{*}{$\mathrm{N}$} & Válido & 316 \\
\hline & Perdidos & 0 \\
\hline \multicolumn{2}{|c|}{ Media } & 20.4 \\
\hline \multicolumn{2}{|c|}{$\begin{array}{l}\text { Desviación } \\
\text { Estándar }\end{array}$} & 2.2 \\
\hline \multicolumn{2}{|c|}{ Rango } & 22 \\
\hline \multicolumn{2}{|c|}{ Mínimo } & 18 \\
\hline \multicolumn{2}{|c|}{ Máximo } & 40 \\
\hline
\end{tabular}

Figura 2: Edad de los estudiantes, Facultad de Negocios, USMA, 2019

En la Figura 3, se muestra el sexo por carrera que estudian los estudiantes. Un $52.2 \%$ son del sexo masculino, y un $47.8 \%$ son del sexo femenino.

\begin{tabular}{|c|c|c|c|c|c|}
\hline & & & $\begin{array}{l}\text { Sexo } \\
\text { Masc }\end{array}$ & Femenino & Total \\
\hline \multirow[t]{6}{*}{ Carrera que estudia } & \multirow[t]{2}{*}{ Negocios internacionales } & Recuento & 76 & 80 & 156 \\
\hline & & $\%$ del total & $24.1 \%$ & $25.3 \%$ & $49.4 \%$ \\
\hline & \multirow[t]{2}{*}{ Logística } & Recuento & 13 & 17 & 30 \\
\hline & & $\%$ del total & $4.1 \%$ & $5.4 \%$ & $9.5 \%$ \\
\hline & \multirow[t]{2}{*}{ Mercadeo } & Recuento & 19 & 17 & 36 \\
\hline & & $\%$ del total & $6.0 \%$ & $5.4 \%$ & $11.4 \%$ \\
\hline
\end{tabular}




\begin{tabular}{|c|c|c|c|c|c|}
\hline \multirow[t]{2}{*}{ Banca y Finanzas } & & Recuento & 16 & 11 & 27 \\
\hline & & $\%$ del total & $5.1 \%$ & $3.5 \%$ & $8.5 \%$ \\
\hline \multirow[t]{2}{*}{ Contabilidad } & & Recuento & 6 & 5 & 11 \\
\hline & & $\%$ del total & $1.9 \%$ & $1.6 \%$ & $3.5 \%$ \\
\hline \multirow{2}{*}{$\begin{array}{l}\text { Administración } \\
\text { empresas }\end{array}$} & de & Recuento & 29 & 16 & 45 \\
\hline & & $\%$ del total & $9.2 \%$ & $5.1 \%$ & $14.2 \%$ \\
\hline \multirow{2}{*}{$\begin{array}{l}\text { Administración } \\
\text { empresas turísticas }\end{array}$} & \multirow{2}{*}{ de } & Recuento & 6 & 5 & 11 \\
\hline & & $\%$ del total & $1.9 \%$ & $1.6 \%$ & $3.5 \%$ \\
\hline & & Recuento & 165 & 151 & 316 \\
\hline & & $\%$ del total & $52.2 \%$ & $47.8 \%$ & $100.0 \%$ \\
\hline
\end{tabular}

Figura 3: Sexo y carrera de los estudiantes, Facultad de Negocios, USMA, 2019

Un 49.4\% (156 estudiantes) son de la carrera de Licenciatura en Negocios Internacionales, un 14.2\% (45 estudiantes) son de la carrera de Licenciatura en Administración de Empresas, un 11.4\% son de la Licenciatura en Mercadeo, un 9.5\% son de la Licenciatura en Logística. En la Figura 2, también vemos que el 8.5\% son de la carrera de Licenciatura en Banca y Finanzas, un 3.5\% son de la Licenciatura en Contabilidad y un 3.5\% son de la Licenciatura en Administración de empresas turísticas.

Al medir el estilo de aprendizaje de los estudiantes de la Facultad de Negocios de la USMA, vemos que prevalecen los tipos convergentes y acomodadores. Un $36.4 \%$ son convergentes y un 35.8 son acomodadores. Por otro lado, un $14.2 \%$ son asimiladores y un $13.6 \%$ son divergentes.

\begin{tabular}{ll|l|l} 
Estilos & Frecuencia & Porcentaje & $\begin{array}{l}\text { Porcentaje } \\
\text { acumulado }\end{array}$ \\
\hline Divergente & 43 & 13.6 & 13.6 \\
\hline Asimilador & 45 & 14.2 & 27.8 \\
\hline Acomodador & 113 & 35.8 & 63.6 \\
\hline Convergente & 115 & 36.4 & 100.0 \\
\hline Total & 316 & 100.0 & \\
\hline
\end{tabular}

Figura 4: Tipos de Estilos de aprendizaje de los estudiantes, Facultad de Negocios, USMA, 2019

Se realiza un aprueba de chi cuadrado para saber si existe diferencias significativas en el grupo analizado. Vemos en la Figura 5 que la significancia es .000 es decir se rechaza la hipótesis nula de que no existe diferencia en el grupo, como, podemos ver en la Figura 5 que hay diferencia ya que prevalece el tipo de estilo de aprendizaje convergente. 


\begin{tabular}{ll}
\hline Chi-cuadrado & 62.076 \\
\hline gl & 3 \\
\hline Sig. asintótica & .000 \\
\hline
\end{tabular}

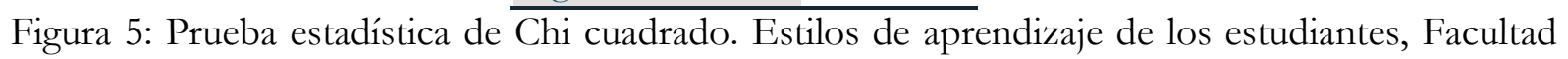
de

Negocios, USMA, 2019

$\mathrm{Al}$ establecer los estilos predominantes de aprendizajes, se señalarán las estrategias metodológicas que se deben desarrollar en la Facultad de Negocios, según los teóricos del tema.

- Actividades manuales.

- Proyectos prácticos.

- Hacer gráficos y mapas.

- Clasificar información.

- Ejercicios de memorización.

- Resolución de problemas prácticos.

- Demostraciones prácticas.

Al observar los resultados obtenidos, cada docente, con base en el modelo de la USMA, debe procurar ambientes de aprendizaje teniendo en cuenta los estilos de cada persona. Por ello la Facultad de Negocios ya desarrolla algunas de estas estrategias, y que deben reforzarse. Estas estrategias son:

- Simuladores de Negocios: Los simuladores de negocio permiten a los estudiantes experimentar en la toma de decisiones de las diferentes actividades de una empresa: producción, finanzas, mercadotecnia, logística de distribución, manejo de marca, etc., sin poner en riesgo mercancía, procesos y el capital de la empresa, lo que pudiera significar en el caso de una mala decisión inclusive la quiebra de esta.

- Investigaciones y uso de Programas estadísticos: El uso de paquetes informáticos para el análisis de datos cualitativos como cuantitativos en los últimos años ha tornado una gran relevancia, programas como Excel, Tableau, SPSS, Microsoft Dynamics, IBM Cognos Analytics, SAP business intelligence, Oracle Business Intelligence, entre otros. Estos programas ayudan en las tareas de investigaciones, tales como el manejo de la información, cálculos estadísticos, el análisis de la información y presentación de resultados. Se solía decir que la información es poder. Pero ahora el poder es entenderla

- Ferias y exposiciones: Las Ferias y Exposiciones, son una, actividad, técnica y estrategia didáctica muy utilizada en el aula. En el caso de uso por parte de los estudiantes, la exposición y Ferias se potencializa como una estrategia didáctica cuyo propósito es incrementar el conocimiento, las habilidades, los valores y las actitudes. 
- Exposición abierta. Consiste en la presentación oral de un tema estructurado, en la que el mensaje presentado por el docente es el inicio para la participación de la clase, pudiendo haber, por lo tanto, contestación, investigación y discusión.

- Estudio de caso. Consiste en la exposición detallada y exhaustiva de una situación real, la cual ha sido investigada y adoptada para ser tratada de tal modo que posibilite un amplio análisis e intercambio de ideas.

- Mapa conceptual y redes semánticas. Son representaciones gráficas de segmentos de información o conocimiento conceptual. El mapa conceptual se diferencia de las redes semánticas porque jerarquiza los conceptos, y las redes no son organizadas necesariamente por niveles jerárquicos.

\section{Conclusiones}

- La realización de la investigación ha permitido conocer los rasgos característicos de los estilos de aprendizaje que identifican a los estudiantes de la Facultad de Negocios de la Universidad Católica Santa María La Antigua. Esto con el fin de poder entender la forma de interpretar en un contexto determinado, e incentivar a los docentes a que diseñen diferentes estrategias para abordar un mismo tema y se pueda alcanzar los resultados planeados.

- La investigación reflejó que la muestra de estudiantes de la Facultad de Negocios de la Universidad Católica Santa María La Antigua, tenía una media de la edad de 20.4 años y que un $52.2 \%$ son del sexo masculino Un 49.4\% (156 estudiantes) son de la carrera de Licenciatura en Negocios Internacionales.

- Al medir el estilo de aprendizaje de los estudiantes de la Facultad de Negocios de la USMA, vemos que prevalecen los tipos convergentes y acomodadores. Un 36.4\% son convergentes y un 35.8 son acomodadores. Por otro lado, un $14.2 \%$ son asimiladores y un $13.6 \%$ son divergentes.

- Producto de conocer el estilo de aprendizaje prevaleciente, se determina que es necesario fomentar el trabajo cooperativo, dinamizan el proceso de enseñanza-aprendizaje, donde se favorezca la participación y socialización. Además, evitar la memorización mecánica del material docente, y que el alumno deja de ser receptor para ser actor de sus propios aprendizajes, y gestor de sus conocimientos.

- La investigación nos lleva a señalar que los docentes de la Facultad de Negocios de la USMA deben desarrollar estrategias didácticas tales como: Simuladores de Negocios, cuando se presentan actividades abstractas que no se relacionan con la realidad. Cuando no pueden relacionar la información con situaciones prácticas, y realizar Investigaciones y uso de Programas estadísticos, Ferias y exposiciones, Exposición abierta, Estudio de caso y Mapa conceptual y redes semánticas. 


\section{Referencias}

[1] CASTRO, S. C. (2005). Los estilos de aprendizaje en la. Caracas: Universidad Pedagógica Experimental Libertador.

[2] CUÉ, J. L. (2012). ESTILOS DE APRENDIZAJE Y ESTRATEGIAS DE APRENDIZAJE:

UN ESTUDIO

EN DISCENTES DE POSTGRADO. México: Revista de Estilos de Aprendizaje.

[3] KLIMENKO, O. (2008). La creatividad como un desafío para la educación del siglo XXI. Medellín: Universidad de Antioquia

[4] MORCHIOI, I. L., \& FRESQUET, A. M. (2014). Aprender en la universidad: análisis de aspectos que lo condicionan desde la perspectiva de profesores y alumnos de la Universidad Nacional de Cuyo (UNCuyo/Argentina) y de la Universidad Federal do Río de Janeiro (UFRJ/Brasil). Brasil: Revista Brasileira de Educação.

[5] ARENAS LOERA, EVA PAOLA., ERIC ORLANDO JIMÉNEZ ROSAS Y JOSÉ LUIS ÁVILA GARCÍA (2014). Estilos de aprendizaje en alumnos universitarios de innovación educativa. Editora Félix Varela, México.

[6] ESPÍRITU OLMOS, ROBERTO Y ANGEL SASTRE CASTILLO. La actitud emprendedora durante la vida académica de los estudiantes universitarios, Facultad de Contabilidad y Administración. Campus Tecomán Universidad de Colima, México.

[7] VENTURA, ANA CLARA. (2011). Estilos de aprendizaje y prácticas de enseñanza en la universidad. Un binomio que sustenta la calidad educativa, Revista Perfiles Educativos, México.

[8] HERNÁNDEZ SAMPIERI, ROBERTO; CARLOS FERNÁNDEZ Y PILAR BAPTISTA. (2014). Metodología de la Investigación. Gta edición. McGraw-Hill, México.

\section{Authorization and Disclaimer}

Los autores autorizan a publicar el presente articulo en la Revista Investigación y Pensamiento Crítico de la Universidad Católica Santa María La Antigua (USMA). La USMA ni los editores son responsables del contenido ni de las implicaciones de lo expresado en el documento. 